\title{
A ESTRUTURA HISTÓRICO-CONCEITUAL DOS PROGRAMAS DE PESQUISA DE DARWIN E LAMARCK E SUA TRANSPOSIÇÃO PARA O AMBIENTE ESCOLAR
}

\author{
Darwin and Lamarck research programs hitoric-conceptual \\ structure and its conversion to the school environment
}

\author{
Argus Vasconcelos de Almeida \\ Jorge Tarcisio da Rocha Falcão ${ }^{2}$
}

Resumo: $\mathrm{O}$ presente trabalho tenta estabelecer uma complementaridade teórica entre uma abordagem epistemológica - a metodologia dos programas de pesquisa de Lakatos - e uma psicológico-cognitivista - a teoria dos campos conceituais de Vergnaud - objetivando a compreensão dos programas de pesquisa lamarckiano e darwiniano em seus respectivos campos de validade. Através da análise da estrutura histórico-conceitual dos dois programas e sua transposição para o ambiente escolar, são constatados e discutidos problemas nos livros didáticos de Biologia e na pesquisa atual sobre o conceito de Evolução entre alunos de diversos níveis escolares. Como resultado destas reflexôes é apontada a teoria dos campos conceituais como um instrumento analítico frutífero do processo de conceitualização dos sujeitos diante de situaçōes envolvendo processos evolutivos.

Unitermos: Lamarck; Darwin; Evolução; programas de pesquisa; campos conceituais.

Abstract: The present work tries to establish a theoretical similarities in complementary among an epistemological approaches between - the methodology of the programs of research of Lakatos - and (a psychological-cognitivist) and - the theory of the conceptual fields of Vergnaud. It - aimsing at the understanding of the programs of research Llamarckian and Ddarwinian programmes of research in theirr respective validity fields. Through the analysis of the historical-conceptual structure of the two programs and itsyour conversion for the school environment, verified and discussed problems in the text books of Biology are identified and discussed as is and in the current research on the concept of Evolution among students atof several school levels. As a result of these reflections the theory of the conceptual fields is pointed out as a fruitful analytical instrument of the conceptualization process inof the subjects front to situations involving evolutionary processes.

Keywords: Lamarck; Darwin; Evolution; research programs; conceptual fields.

\section{Introdução}

A Teoria Sintética da Evolução é considerada a teoria mais unificadora dentre todas as teorias biológicas. Antes dela, as diversas áreas das ciências biológicas eram independentes, reunidas fragmentariamente na chamada História Natural. Só a partir desta surgiu a Biologia com o seu estatuto e paradigmas unificadores como ciência.

Entretanto, do ponto de vista da sua transposição didática, isto é, a transformação do "saber dos sábios" em saber pronto para ser ensinado (Chevallard, 1985) o tema é problemático. De fato, o conceito de evolução mostra-se permeado por obstáculos epistemológicos, de fundo ideológico, filosófico e teológico, o que torna sua abordagem em contexto de sala de aula particularmente difícil, tanto no ensino, por parte dos professores, quanto na aprendizagem, por parte dos alunos. Deve-se enfatizar que a compreensão dos processos evolutivos tem um papel central na conceitualização de todos os temas da Biologia.

\footnotetext{
${ }^{1}$ Professor Adjunto do Departamento de Biologia da Universidade Federal Rural de Pernambuco; doutorando em Psicologia Cognitiva da UFPE.E-mail:argus@ufrpe.br

${ }^{2}$ Professor Adjunto do Departamento de Psicologia da UFPE e da Pós-Graduação em Psicologia Cognitiva da UFPE. E-mail: jtrf@terra.com.br
} 
Por outro lado, é freqüente em vários livros didáticos de Biologia adotados no Brasil a abordagem do tema como concluído, desprovido de contextualização histórica para a compreensão, por parte dos alunos, de como os conceitos foram desenvolvidos ao longo do tempo. No lugar da supracitada contextualização, apresentam-se: a dicotomia teórica entre lamarckismo x darwinismo, a viagem de Darwin no Beagle e a sua demora na publicação da "Origem das Espécies". Segundo Rumelhard, citado por Astolfi \& Develay (1995: 49), "trata-se de um fenômeno geral denominado de 'processo de dogmatização', como uma reificação de teorias científicas no âmbito do saber escolar".

Deve-se estar consciente que o termo Evolução é uma metáfora viva, portanto, contém necessariamente uma certa carga de ambigüidade polissêmica. Se, como enfatiza Lewontin (2002: 9), "não se pode fazer ciência sem usar uma linguagem cheia de metáforas", deve-se atentar, como adverte Da Rocha Falcão (1996: 145), que "se metáforas podem ser usadas como 'amplificadores culturais', é preciso não perder de vista que elas podem desviar completamente o indivíduo da compreensão conceitual desejada".

Nesse sentido, convém considerar que os principais construtores da teoria, não usaram o termo "evolução" nas suas obras. Darwin escreveu inicialmente o termo "transmutação" e depois usou a expressão "descendência com modificação" e Lamarck usou as expressōes "progressão" e "aperfeiçoamento" (Martins, 1997: 34).

Originalmente o termo "evolução" foi cunhado em 1744 pelo biólogo alemão Albrecht von Haller, para descrever a teoria de que os embriōes crescem de homúnculos préformados contidos no óvulo ou no esperma humano. Haller escolheu o termo cuidadosamente, porque a palavra latina evolvere significa "desenrolar" (Gould, 1987: 26). Tudo indica que o próprio Darwin, inicialmente, não ficou satisfeito com o termo e preferia a sua expressão: "descendência com modificação" (Gould, 1987: 29).

Para Bowler (1975: 95) o termo "evolução" tinha significado ontogenético e passou a ser usado em Biologia, da maneira como hoje o conhecemos, graças à popularização que Herbert Spencer fez do mesmo (Gould, 1987: 25).

\section{O Contexto Histórico das Ciências Biológicas}

O que poderia ter induzido um homem de quase 55 anos a abandonar a sua visão do mundo anterior, substituindo-a por uma outra, a tal ponto revolucionária, que ninguém antes dele a havia sustentado? Pergunta-se Mayr (1998: 386) com admiração, no capítulo dedicado à teoria de Lamarck, da sua obra sobre a História da Biologia.

Lamarck desenvolveu o seu programa de pesquisa numa das épocas mais revolucionárias da história da humanidade, tanto em termos políticos quanto intelectuais: foi a época da Revolução Francesa e do movimento de independência das colônias inglesas norte-americanas (com desdobramentos no Bolivarismo sul-americano e mesmo no nacionalismo republicanista da Inconfidência Mineira no Brasil), bem como do Iluminismo (com o Enciclopedismo). Tal contexto de aguçamento do criticismo muito provavelmente contribuiu para a ousadia de suas conjecturas. Durante tal período houve um importante movimento de compilação e divulgação do saber científico acumulado, no contexto do qual este saber foi convocado a descer da "torre de marfim" dos salóes da aristocracia e passar a comprometer-se com as necessidades físicas e intelectuais da cidadania burguesa nascente.

A 10 de junho de 1793, através do decreto da Convenção Nacional, a antiga instituição do Gabinete e Jardim do Rei, é substituída pela criação do Museu Nacional de História Natural e Lamarck assume nessa instituição nascente como titular da cadeira dos animais sem 
vértebras (Conry, 1994: 560), passando a encarregar-se da coleção de moluscos, após a morte do seu amigo Bruguière (Mayr, 1998: 388). Segundo Conry (1994), este fato, associado ao deslocamento dos seus interesses de pesquisa da botânica para a zoologia, teve profundas conseqüências na formulação do seu programa de pesquisa e visão da natureza.

Em relação ao contexto do trabalho de Darwin, escreve Canguilhem (1977: 93) que, em 1859, no campo da biologia geral, já estavam constituídos cientificamente, isto é, a posse dos princípios heurísticos, os conceitos operatórios e as técnicas experimentais das pesquisas sobre a origem da vida de seres unicelulares, ao desenvolvimento e à estrutura elementar dos seres pluricelulares e às funções de manutenção e de comportamento do ser vivo individual.

Enquanto isso, a História Natural, nas áreas da zoologia e botânica, desenvolvia pesquisas predominantemente descritivas da fauna e flora das regiōes desconhecidas do mundo. Ora, foi daí que Darwin recolheu seus dados de pesquisa como naturalista e pouco articulou com a biologia experimental, com exceção da embriologia, as idéias e conceitos para a sua construção teórica.

Daí a razão de que na época, o problema da origem das espécies, teve pouca ou nenhuma compreensão por parte dos pesquisadores em biologia experimental. Como afirma Canguilhem (1977: 94), a maneira de pensar e os métodos de trabalho dos fisiologistas, microbiologistas e citologistas, eram completamente diferentes: eram pesquisas de laboratório, operando com indivíduos, determinando constantes e estruturas funcionais e mecanismos de regulação dos organismos. Na microbiologia nascente, Pasteur sustentava a idéia de que o ser vivo só procede de outro ser vivo, o semelhante só pode originar-se do semelhante, reforçando a desconfiança em relação a qualquer teoria de modificação das espécies. Os fatos de populações, o tratamento probabilístico dos dados, as regras e os conceitos da sistemática vegetal ou animal, não faziam parte do seu quadro metodológico, ao contrário, constituíam-se num obstáculo à sua compreensão.

Reforçando argumentos acerca da disparidade acima aludida, Mayr (1998: 602), alega a existência de um fosso intransponível entre os biólogos experimentais, de um lado, e os naturalistas, do outro: alega o autor que, os experimentalistas e os naturalistas não apenas divergiam nos seus métodos, mas também tendiam a formular questões diferentes. Tratava-se, pois, de duas diferentes tradições de pesquisa.

\section{O Programa de Pesquisa Transformista de Lamarck}

Lamarck desenvolveu a sua teoria transformista em diversas obras ao longo do tempo, entre as quais: Recherches sur l'organisation des corps vivants (1800); Philosophie zoologique (1809); Histoire naturelle des animaux sans vertèbres (1815), além de palestras e discursos, tais como: Discours d'overture: An VIII (1800), An IX (1801), An X (1802) e An XI (1803) (Martins, 1997: 34).

Embora o objetivo central do programa de Lamarck não fosse a evolução orgânica e tampouco a origem das espécies, a sua teoria é considerada pelos historiadores da biologia como a primeira explicação sistemática da evolução dos seres vivos.

$\mathrm{Na}$ verdade, o seu objetivo teórico principal era a compatibilização entre a sua crença deísta e a extinção dos seres vivos, constatada pela paleontologia. Embora existam controvérsias a respeito das suas teorias centrais (Buckhardt, 1970) para resolver o dilema teórico-teológico erigiu, o que pode ser considerado como o "núcleo firme" (Lakatos, 1989: 37) do seu programa, formado por duas teorias sobre o mecanismo da transformação dos seres vivos: a organização progressivamente complexa dos seres vivos e a sua capacidade de reação às mudanças ambientais (Mayr, 1998: 396). 
A primeira teoria proposta por Lamarck pressupunha um potencial inato da vida, uma lei da natureza, que dispensava maiores explicaçôes. A segunda era necessária para explicar todos os tipos de adaptaçôes dos seres vivos no transcurso do tempo. Portanto, o ambiente produzia necessidades e atividades no organismo, e estas, por sua vez, operavam variações adaptativas.

A crença na possibilidade e necessidade de "transformação" dos seres vivos já era compartilhada por alguns zoólogos da época como Buffon, por exemplo. Entretanto existia a noção de que os seres vivos não se extinguiram, mas se transformaram, pois tal extinção não seria compatível com o poder e a bondade do Criador.

Como cinturão protetor do núcleo firme do seu programa, Lamarck desenvolveu algumas teorias auxiliares, entre as quais, uma explicação fisiológica, baseada nas idéias de Cabanis, de natureza mecanicista, para explicar as adaptaçôes dos organismos, causadas pelo esforço de satisfazer às novas necessidades, invocando a ação de estímulos extrínsecos e a movimentação no corpo de fluidos sutis. Estas duas teorias eram complementadas pelas noções de que a transformação dos seres vivos dava-se pela ação de um tempo muito longo e pela sua crença deísta na ação de um deus que, ao criar o universo "havia dado um passo atrás" na criaçãoo da vida.

Do ponto de vista filosófico adotou a weltanshauung, então corrente de um universo regido por leis, dos inanimados até os corpos organizados. A partir da filosofia otimista de Leibniz, acreditava numa continuidade, harmonia e plenitude do universo.

Como a maioria dos naturalistas do século XVIII, Lamarck era um uniformitarista e gradualista convicto, postulava uma imensa idade da Terra, com modificaçóes constantes e lentas.

Segundo Mayr (1998: 388), quando Lamarck assumiu a curadoria da coleção de moluscos do Museu de História Natural nos fins de 1790, entrou em contato com uma coleção completa de moluscos fósseis e recentes, estabelecendo séries filéticas, que resolviam o problema da extinção das espécies. Finalmente, estabeleceu a teoria de que os seres vivos existiam numa forma de gradação, dos mais simples e primitivos até os mais complexos (Buckhardt, 1970).

Incorporou depois como forma de "leis", a noção de que os órgãos ou partes do organismo eram modificados pelo uso e desuso e de que estas modificaçôes poderiam ser herdadas desde que fossem comuns a ambos os sexos; teorias estas que eram compartilhadas pela comunidade dos naturalistas da época. Este conjunto de teorias e hipóteses constitui a heurística negativa do seu programa de pesquisa, defendendo o núcleo firme contra as anomalias e refutaçōes (v. Lakatos, 1987; Silveira, 1996).

A heurística positiva do seu programa é constituída por teorias, orientaçōes e influências que guiaram pesquisas posteriores e que reforçaram o núcleo firme transformista e algumas teorias auxiliares.

Tal núcleo transformista enfatiza a transformação dos seres vivos como alternativa à proposição de extinções e criaçôes sucessivas de seres vivos: estes simplesmente transformar-seiam ao longo do tempo.

Assim, a teoria da progressão histórica das espécies, bem como a teoria desenvolvida pelo seu simpatizante Étienne Geoffroy de Saint-Hilaire sobre a unidade de composiçāo do reino animal, tiveram conseqüências na paleontologia. Pela primeira vez, a biologia foi designada como uma nova ciência na sua obra Recherches sur l'organisation des corps vivants (Conry, 1994). O trabalho de pesquisa de Lamarck como sistemata, às vezes negligenciado pela história, deixou conseqüências frutíferas na classificação botânica, com a introdução do instrumento das chaves de identificação dicotômicas e um completo sistema animal de invertebrados (Buckhardt, 1972). 
O seu programa de pesquisa deu origem a toda uma série de pesquisas influenciada pelo ambientalismo como fator preponderante na interpretação dos fenômenos evolutivos, tendo conseqüências até nas ciências humanas, como por exemplo o "efeito Baldwin" (Baldwin, 1896). Finalmente, quando assumiu a direção do Museu de História Natural, implementou reformas influenciadas por convicções ideológicas do ideário revolucionário francês de 1789, que via na natureza a reprodução da organização da sociedade humana. Assim, cabia aos museus apresentar a representação como teatros da natureza (Conry, 1994: 583).

A avaliação do programa de Lamarck permite-nos caracterizá-lo como inicialmente teoricamente progressivo (Silveira, 1996: 223), pois fez algumas predições na descoberta de alguns fósseis de invertebrados e retrodições de fósseis de vertebrados e plantas. Entretanto, o programa era empiricamente regressivo, pois mesmo com ajustes ad hoc nas teorias e hipóteses observacionais do seu cinturão protetor, entrou em rápida degeneração no início da década de vinte do século XIX, sendo considerado como uma mera especulação, sem comprovação empírica por zoólogos do porte de Cuvier, por exemplo.

Entretanto, a maior parte dos atuais livros didáticos de Biologia, como por exemplo: Amabis \& Martho (1997: 218); Soares (1999: 261); Uzunian \& Birner (2001: 713); Brito \& Favaretto (s/d: 187), afirma Lamarck, teria baseado a sua teoria em duas suposiçôes:

1 - Lei do uso e desuso: de acordo com tal lei, quanto mais uma parte ou órgão do corpo é usado mais se desenvolve, contrariamente, as partes não usadas enfraquecem, atrofiam, chegando a desaparecer.

2 - Lei da herança dos caracteres adquiridos: segundo Lamarck, qualquer animal poderia transmitir aos seus descendentes atrofias físicas decorrentes do desuso ou hipertrofias decorrentes de uso; portanto, ele acreditaria, conforme apresentado em tais livros didáticos, que as novas espécies apareciam por evolução devido à perda ou aquisição de caracteres.

Martins (1997; 1998), muito acertadamente, não concorda com esta simplificação e faz nos trabalhos citados uma forte crítica da história do tema contida nos livros didáticos de Biologia.

Segundo a autora (1998: 35), a idéia da "progressão" das espécies começou a aparecer nas diferentes obras de Lamarck, a partir de 1800. De acordo com essa idéia, para que ocorresse a variação das espécies, haveria a necessidade de mudanças nas circunstâncias a que os animais estavam expostos a um tempo considerável.

Afirma Bizzo (1991: 259), que a identificação direta e imediata entre a crença na herança das características adquiridas e a teoria de Lamarck é, antes de tudo, um equívoco. Pois, não se pode ligar a crença de toda uma época ao pensamento de uma só pessoa. Opina o mesmo autor ser estranho que Lamarck seja lembrado, inclusive por professores de Biologia, como criador da crença na herança dos caracteres adquiridos - o que não é verdade - e não seja conhecido por ter sido o criador do termo Biologia para designar uma nova disciplina - o que é verdade.

Nesse contexto, Buckhardt $(1970,1972)$ enfatiza a necessidade do reconhecimento do trabalho de Lamarck para o desenvolvimento da Biologia como ciência. 


\section{O Programa de Pesquisa da Descendência com Modificação de Darwin}

Darwin construiu a sua teoria da Descendência Com Modificação em três obras fundamentais: The origin of species by means of natural selection, publicado em 1859 (1952); The variation of animals and plants under domestication (1868) e The descent of man publicado em 1871 (1952). A primeira obra é um resumo de um texto mais volumoso sobre a teoria da seleção natural, onde deliberadamente evitou abordar a origem do homem (Bowler, 1989: 498). A cada nova edição da Origem, Darwin tentava responder aos seus críticos e remanejava o seu arsenal teórico tentando dar mais coerência a sua teoria principal.

Os objetivos teóricos do programa de pesquisa de Darwin eram, em primeiro lugar, negar o fixismo das espécies e, em segundo lugar, negar a criação em separado das mesmas.

O programa de pesquisa de Darwin tem como núcleo firme uma hipótese observacional centrada na imensa variedade dos seres vivos, seja na condição de domesticação, seja na condição selvagem. Sobre estas variações atua o mecanismo operatório da seleção natural. Este núcleo firme foi defendido por um conjunto de 17 teorias e hipóteses auxiliares, que podem ser consideradas como o seu cinturão protetor, constituindo-se na sua heurística negativa, sob cuja base se estabelecem as condições iniciais (Lakatos, 1989: 230) de defesa do núcleo firme contra as anomalias e refutaçóes que surgiram ao longo do tempo.

A primeira das teorias auxiliares foi formulada através da expressão: sobrevivência dos mais aptos, tirada de Spencer, que Darwin considerava como uma forma mais elaborada da teoria da seleção natural. Tanto uma como a outra foram frontalmente criticadas. Segundo Mayr (1998: 579), Darwin tentou substituir a expressão "seleção natural" por "preservação natural", entretanto, depois ponderou que a segunda expressão não tinha tanta conotação operativa quanto a primeira, que foi acusada de antropocentrismo. Por outro lado, a expressão spenceriana "sobrevivência dos mais aptos", seria tautológica: quem sobrevive? os mais aptos; quem são os mais aptos? os que sobrevivem!

Em relação à teoria da seleção natural, Darwin teve um sério concorrente na sua formulação, que foi o naturalista inglês Alfred Russel Wallace (1823-1913), que chegou independentemente à idéia da evolução por seleção natural. Segundo suas mesmas palavras, numa carta a Darwin de 1858, fazia alusão "sobre a tendência das variedades a se afastarem indefinidamente do tipo primitivo" (Thuillier, 1994: 205), o que ameaçava a prioridade de Darwin na apresentação da sua teoria. A solução encontrada foi a apresentação conjunta dos dois trabalhos em sessão da Sociedade Lineana de Londres feita pelos amigos de Darwin: Lyell e Hooker, os quais tiveram o cuidado, nesta ocasiáo, de apresentar o trabalho de Darwin em primeiro lugar e depois o de Wallace.

A expressão teórica auxiliar era a da luta pela existência, que Darwin enfatizava o seu uso metafórico, foi tirada da obra de Malthus sobre populaçóes, na qual o autor sustentava o crescimento em escala geométrica da população diante do crescimento em escala aritmética dos recursos alimentares. Darwin transpôs esta noção para a natureza, articulando-a com as observaçôes da imensa capacidade reprodutiva dos seres vivos e da estabilidade das populaçôes. Daí concluía que deveria haver uma encarniçada luta pela existência, da qual só sobreviveriam os mais aptos.

Três teorias auxiliares do programa darwiniano foram adotadas de naturalistas que o precederam, entre os quais Lamarck: a primeira era da ação do meio ambiente como causa das variações; a segunda era do uso e desuso das partes e órgãos do organismo que atuaria independentemente da seleção natural e finalmente, a terceira, da hereditariedade dos caracte res adquiridos, na qual Darwin discute, como é próprio do seu estilo, diversos exemplos de 
plantas e animais, nos quais a "mudança de hábitos produz efeitos hereditários" (Darwin, 1961: 11).

É consenso entre os historiadores da biologia as dificuldades teóricas de Darwin para compatibilizar a sua teoria de descendência com modificação com as suas concepções sobre hereditariedade. Para alguns, tais como Thuillier (1994: 200) e Mayr (1998: 805), Darwin não teria tomado conhecimento do famoso estudo de Mendel sobre Experiências sobre plantas hibridas, o que lhe permitiria, em princípio, retificar e completar sua teoria. Entretanto, para outros, tais como Bizzo (1991: 136-137), a versão de Bateson, segundo a qual Darwin teria total desconhecimento dos trabalhos de Mendel, é rigorosamente incorreta, pois em alguns dos manuscritos de Darwin ele demonstra ter conhecimento do trabalho de Mendel sobre a fertilização de Phaseolus multiflorus, que muito interessava a Darwin, quando o comparava com os experimentos de Hoffman de 1869.

A sua "hipótese provisória" da pangênese permitia-lhe conceber a transmissão hereditária segundo um modelo mecanicista e possuía grande semelhança com a original hipocrática, além do que, justificava e explicava a herança dos caracteres adquiridos. Ele supunha que as células de todas as partes do corpo emitiam pequenos grãos ou átomos, denominados de gêmulas, que circulavam no organismo e se agregavam como elementos sexuais. Segundo Thuillier (1994: 202), depois foi pior, pois levou a sério uma idéia teoricamente discutível, embora aceita por outros naturalistas, como a hereditariedade por mistura ou intermediária, considerada pelo autor como um "desastre teórico", colocando a possibilidade de manutenção das variações em uma população num beco sem saída. Segundo o mesmo autor, Darwin chegava no final da sua vida tornando-se cada vez mais "lamarckiano", ao contrário dos seus seguidores, cada vez mais selecionistas.

Outra teoria auxiliar do cinto de segurança do programa de Darwin era uma correspondência estabelecida entre a seleção natural e a seleção artificial dos criadores de animais, horticultores e jardineiros que manipulavam os organismos na condição de domesticação, as raças e variedades produzidas por estes em seus cruzamentos selecionados, serviram de argumento empírico para explicar o mecanismo da seleção natural. Estas variedades produzidas eram consideradas por Darwin como espécies nascentes, no que foi contestado frontalmente por Fleming Jenkin, que sustentava que animais e plantas possuíam uma "esfera de variação" que não poderia ser ultrapassada, além de apresentarem uma "tendência ao retorno" à conformação da "cepa original" (Thuillier, 1994: 213). Estas críticas, mesmo que tenham vindo de um não naturalista, calaram fundo em Darwin, que considerava Jenkin um dos seus críticos mais perspicazes.

Tais críticas o obrigaram a remanejamentos teóricos do seu programa em edições posteriores da Origem, tais como a teoria auxiliar de que as variaçôes deveriam ser favoráveis e simultâneas para operar efetivamente, além de uma outra teoria de que algumas variaçóes poderiam ser neutras, quando percebeu a possibilidade da existência de variações que não eram nem vantajosas e nem nocivas, constituindo-se numa explicação ad hoc do polimorfismo de certas espécies animais e vegetais.

Uma outra teoria auxiliar era a do gradualismo contínuo. Darwin enfatizava que a seleção natural atuava sobre as variações em tempo muito longo e, gradualmente, para rejeitar o catastrofismo, tinha como uma de suas máximas preferidas de que "a natureza não dá saltos". Assim, rejeitava as variações bruscas que, segundo ele, equivaleriam a "entrar no domínio dos milagres" (Thuillier, 1994: 200). Este gradualismo foi fortemente influenciado pelas teorias geológicas de Huntton e Lyell. 
Outra teoria auxiliar que Darwin (1974) expôs minuciosamente na obra $A$ descendência do homem, foi a da seleção sexual, que foi por ele cuidadosamente diferenciada da seleção natural, pois dependia da luta entre os indivíduos de um sexo, geralmente os machos, para assegurar a posse do outro sexo, que para Darwin se constituía num processo evolutivo especial (Gould, 2002: 45).

Diante das críticas de que as pequenas variações poderiam ser "apagadas" pela hereditariedade intermediária, Darwin, para tornar o seu programa mais coerente, nas ediçóes posteriores da Origem, cada vez mais enfatizou a importância da ação do ambiente ou ação direta das condições externas. Segundo suas próprias palavras: "Sem dúvida, eu atribuí inicialmente pouco peso à ação direta das condições" (Darwin citado por Thuillier, 1994: 204). Argumentava que a ação direta e definida das mudanças nas condições ambientais é capaz de transformar uma população num determinado sentido, sendo suficiente que "uma uniformidade de causas" provoca uma "uniformidade de efeitos". Graças a este remanejamento teórico, tornava-se possível limitar o desastre teórico da teoria da hereditariedade intermediária. Em segundo lugar, Darwin introduziu no "cinto de segurança" do seu programa uma hipótese observacional de que os organismos possuiriam uma tendência a variar numa mesma direção, impedindo assim a ação dissolvente da hereditariedade intermediária.

A atuação da seleção natural sobre as variações ocorrentes nas espécies de seres vivos provocaria nas mesmas uma divergência de caracteres. Como argumenta Darwin (1961: 107), esta teoria dispensava até mesmo a condição de isolamento geográfico na formação das espécies de descendência com modificação.

Segundo Mayr (1998: 535) a grande novidade de Darwin foi interpretar todos estes processos através de um pensamento populacional, substituindo o nominalismo e o essencialismo tradicional na abordagem do estudo das espécies.

A heurística positiva do seu programa foi a de orientar diversas pesquisas que tinham como fim a justificação do seu sistema teórico, assim houve uma verdadeira corrida pelos estudos paleontológicos de campo, em busca dos registros fósseis e geológicos, dos "elos perdidos" da descendência com modificação nos organismos.

Por outro lado, um número expressivo de trabalhos em História Natural iniciou as tentativas de explicar o processo de especiação, ou de como nasciam as espécies. Para tanto, estas pesquisas eram articuladas com os trabalhos de levantamento das homologias morfológicas entre os animais, com os da origem da diversidade e da distribuição geográfica dos organismos nas diversas regiōes do globo terrestre (Gould, 2002: 80).

Paralelamente, diversos naturalistas tentavam estudar o significado das adaptações dos organismos diante das alterações ambientais. Tais estudos, anteriormente hegemonizados pelos lamarckistas, passaram a ter uma orientação predominantemente darwiniana.

A classificação dos organismos, usada por Darwin como uma das provas do seu parentesco e filiação nos sistemas naturais, teve um renascimento sob o novo paradigma teórico. Desta vez, sem o enfoque no padrão essencialista e sim populacional, dando origem à sistemática evolutiva. Entretanto, o enfoque essencialista na sistemática ainda resistiu dominante por muito tempo.

Finalmente, dois aspectos da heurística positiva do programa de Darwin, que ele conscientemente tratava com cautela e relutância: a origem do homem e a origem da vida. $\mathrm{O}$ primeiro só foi objeto de um trabalho publicado dez anos depois da Origem e o segundo foi deixado para que seus seguidores desenvolvessem, o que foi feito através do referencial teórico do materialismo mecanicista. 
No final da sua vida, Darwin tornava-se cada vez mais teoricamente pluralista em relação à origem das espécies. Com o objetivo de dar mais precisão ao seu programa de pesquisa, introduziu algumas incoerências, sem, entretanto, aumentar a sua capacidade explicativa, entrando em rápida degeneração.

Após a sua morte, no final do século XIX, os seus seguidores estavam cada vez mais divididos, havendo então algumas teorias alternativas para explicar a origem das espécies.

A moderna Teoria Sintética da Evolução pode ser resumida nos seguintes termos: 1) as populações contêm variações genéticas que surgem através de mutações ao acaso (mais precisamente "mutações cegas"), isto é, não dirigida adaptativamente, e recombinação; 2) as populações evoluem por mudanças nas freqüências gênicas trazidas pela deriva genética aleatória, fluxo gênico e, especialmente, pela seleção natural; 3) a maior parte das variantes genéticas adaptativas apresentam pequenos efeitos fenotípicos individuais, de tal modo que as mudanças fenotípicas são graduais (embora alguns alelos com efeitos discretos possam ser vantajosos, como em certos polimorfismos cromáticos); 4) a diversificação vem através da especiação, a qual ordinariamente acarreta a evolução gradual do isolamento reprodutivo entre populaçôes; 5) esses processos, se continuados por tempo suficientemente longo, dão origem a mudanças de tal magnitude que facultam a designação de níveis taxonômicos superiores (gêneros, famílias, e assim por diante) (Futuyma, 1995: 13).

Finalmente é necessário concluir com Futuyma, (1995: 16) hoje a afirmação de que os organismos descenderam, com modificações, a partir de ancestrais comuns, não é uma teoria, é um fato.

\section{As Atuais Controvérsias da Biologia Evolutiva}

A partir dos anos 60 , surgiram duas tendências antagônicas no seio do neodarwinismo, defendendo dois pontos de vista radicalmente opostos sobre o papel da seleção natural. Uma sustenta que ela é o agente exclusivo da evolução das espécies, que haveria de conduzir ao chamado "ultradarwinismo". A outra, pelo contrário, sustenta que o acaso desempenha um papel pelo menos tão grande como a seleção natural na evolução das espécies, é a teoria neutralista do geneticista japonês Motoo Kimura.

Na virada dos anos 70, os paleontólogos americanos Stephen J. Gould e Niles Eldredge propuseram um modelo de evolução chamado de Equilíbrio Pontuado, que questionava o modelo gradual da evolução. Segundo esses autores, citados por Blanc (1990: 135), a evolução parecia operar muitas vezes por equilíbrios pontuados: após uma existência de vários milhôes de anos num estado estável (isto é, equilibrado), uma espécie dava bruscamente, sem transição aparente, lugar a uma nova espécie com características nitidamente diferentes. Os períodos de "estase" evolutiva eram interrompidos por períodos de "pontuações" (especiações rápidas).

Como escreve o autor (op. cit.: 7), não é sobre a realidade da evolução que o debate científico da nossa época é travado. Atualmente, a principal controvérsia científica também não incide sobre o confronto entre lamarckismo e darwinismo, como insistem em reproduzir os autores dos livros didáticos de Biologia. Desde os meados do século XX o neodarwinismo colocou-se numa posição de incontestável destaque no mundo científico. A partir dos anos 70, novas correntes críticas do neodarwinismo começaram a manifestar-se a partir do Japão (Kimura) e dos Estados Unidos (Eldredge e Gould). A controvérsia evolutiva incide particularmente em dois pontos. Primeiro, que lugar ocupa verdadeiramente a seleção natural de Darwin na evolução? Não terá o acaso tanta ou mais intervenção quanto ela? Em segundo lugar, como surgem as espécies? 
Modernamente, como escreve o mesmo autor (op. cit.: 147), a partir dos trabalhos da corrente ultradarwinista, surgiu nos Estados Unidos em 1975, a obra intitulada Sociobiology: The New Synthesis, cujo autor é o entomologista, especialista em insetos sociais, Edward O. Wilson, que proclamava-se o fundador de uma nova disciplina, a Sociobiologia, que tinha como objetivo o estudo científico de todas as sociedades animais e humanas à luz da teoria neodarwinista da evolução. A obra suscitou diversas reações, a grande maioria dos meios científicos aprovou-a pelo esforço de representar uma nova síntese teórica da biologia evolutiva e uma minoria ativa de cientistas denunciou-a imediatamente como ideológica e reacionária, como uma tentativa de resgatar o darwinismo social. O debate ainda não está esgotado e continua mais vivo do que nunca, extravasando do campo das Ciências Biológicas para as Ciências Humanas.

Bizzo (1991: 274) conclui que os conteúdos ligados ao darwinismo estão altamente imbricados na trama social, pois existem referências muito fortes para os conteúdos biológicos ligados à Evolução. No contexto atual do ensino isto se revela igualmente relevante diante da expansão do ideário neoliberal. Como diz o autor, vivemos um momento especialmente favorável à utilização da Biologia como uma arma social, pois, o darwinismo se apresenta como um dos mais úteis conjuntos de idéias que podem ser utilizadas para convencer os cidadãos de que as idéias neoliberais são "naturais", tais como a associação entre "evolução" e "progresso" e o crescimento recente das doutrinas baseadas no determinismo biológico.

\section{Darwin x Lamarck no Ambiente Escolar}

No ensino da Evolução, nota-se que existem diversos obstáculos na construção do conhecimento do tema por parte dos alunos, quando submetidos a um processo de aquisição de conhecimentos através da sua mera transmissão (Gené, 1991: 22).

Estudiosos citados por Gené em seu trabalho, constataram a tendência que têm os alunos de aceitarem a teoria "lamarckista" como sendo válida para explicar os mecanismos do processo evolutivo, por exemplo, Lucas, citado pelo autor, desde 1971, pela primeira vez constatou a semelhança entre as explicaçóes dos alunos a respeito da evolução dos seres vivos com as de Lamarck a respeito do tema. A partir deste trabalho diversos autores constataram situações semelhantes em estudantes de diversos níveis escolares.

Entretanto, estas idéias de cunho "lamarckista" têm sido constatadas em estudantes de muitos países distantes entre si, tanto geográfica, quanto culturalmente, como os citados por Gené (1991: 22), Jung Wirt, em 1975, em escolares de Israel; Brumby, em 1980, em estudantes ingleses; Hallden, em 1988, em adolescentes suecos; Kinnear e Martin, em 1983, em estudantes australianos.

Quando o mesmo Gené (1991) usou a aplicação de entrevistas e questionários com os alunos, envolvendo situações problemas sobre a Evolução, tais como:

As aves aquáticas que nadam pela superficie da água utilizam-se das patas para sua impulsão que apresentam uma membrana interdigital desenvolvida. Esta membrana faz com que o movimento das patas se torne mais eficaz e portanto, promova o seu deslocamento. Como você explica o surgimento desta membrana interdigital? (op. cit.: 22).

As respostas dos alunos invariavelmente eram de que a referida membrana tinha surgido pelo esforço continuado da ave em se deslocar na água e que posteriormente esta característica havia sido transmitida aos seus descendentes. 
Os estudos sobre o tema realizados no Brasil ainda estão iniciando, destacando-se como um dos mais importantes o trabalho de Bizzo (1991), em sua tese de doutorado sobre o ensino de Evolução e história do darwinismo que, através de entrevistas e questionários aplicados aos estudantes do ensino paulista, constatou o mesmo tipo de explicações de cunho "lamarckista" para os mecanismos do processo evolutivo, ressaltando o significado da Evolução que parece ser muito mais amplo, estando suas idéias relacionadas com progresso, crescimento e melhoramento dos seres vivos, principalmente do homem (Bizzo, 1991: VI).

Entretanto, o autor faz ressalvas à classificação de lamarckistas para as explicaçôes dos alunos, ponderando que não se deve fazer uma simplificação histórica do problema, pois a exposição simplista dos modelos lamarckistas, geralmente apresentados como errados ou tolos pelos livros-texto, tenderia a retrair os alunos, desencorajando-os a debater suas idéias e testar seus modelos contra novos fatos da realidade (op. cit.: 195).

Os livros didáticos de Biologia (ou História Natural), iniciam a tratar o tema Evolução a partir dos anos 30 do século passado. Nestes, o tema ainda é tratado timidamente e a dicotomia teórica entre o Darwinismo x Lamarckismo ainda não estava estabelecida. $\mathrm{O}$ tópico sobre Evolução é tratado ainda como recurso teórico nos capítulos referentes à Paleontologia, no estudo dos fósseis ou no de Hereditariedade. Nesses livros-texto, um expressivo número de antigos naturalistas é referenciado como precursores da teoria da Evolução.

A partir dos anos 60, o ensino das chamadas Ciências Naturais, e particularmente da Biologia, foi fortemente influenciado pela publicação do BSCS (Biological Sciences Curriculum Study) - Versão Azul, traduzido no Brasil como uma "inovação" no ensino das ciências com os "objetivos de atualizar os conteúdos, dar aos alunos uma visão abrangente das várias ciências e tornar o ensino experimental” como escreve Krasilchik (1987: 8), com a participação de pesquisadores brasileiros como a própria Myriam Krasilchik e Oswaldo FrotaPessoa (Fracalanza, 1985: 147).

É nesta obra que pela primeira vez é estabelecido o confronto teórico entre o Lamarckismo e o Darwinismo como "dois pontos de vista em conflito" (BSCS, 1965: 38). Em primeiro lugar a teoria lamarckiana é rebaixada a uma mera "hipótese", que não teria base experimental e, muito menos, a "prova" da transmissão dos caracteres adquiridos. No texto, as especulações de Lamarck são confrontadas ao modelo canônico do trabalho científico de Darwin, que com seu trabalho "experimental" teria "provado" a sua teoria da evolução através da seleção natural. É esta visão distorcida e superficial da história que vai perpetuar-se na maior parte dos livros didáticos de Biologia e nas práticas pedagógicas dos professores da área, até a atualidade.

No BSCS, também pela primeira vez é apresentado o exemplo da figura da girafa para ilustrar as diferenças de abordagem entre Lamarck e Darwin sobre o alongamento do seu pescoço. Tal exemplo foi reproduzido desde então na maioria dos livros didáticos de Biologia até a atualidade, constituindo-se numa iconografia clássica para estabelecer a controvérsia entre Lamarck e Darwin.

Quando os alunos, em diversos níveis de escolaridade, são colocados diante de situações problemáticas envolvendo conceitos centrais da biologia evolutiva, tais como, a evolução como tal e os mecanismos do processo evolutivo, como os estudados por Gené (1991: 23-24), Bizzo (1991: 216-228) e Jensen \& Finlay (1995: 156-157), geralmente não apresentam dificuldades em aceitar o fato da evolução. Entretanto, em relação aos mecanismos do processo evolutivo, apresentam representaçôes e mobilizam conceitos relacionados às teorias do uso e desuso das partes, da herança dos caracteres adquiridos, da intencionalidade e utilidade da modificação e da influência do ambiente nas modificações dos organismos. Tais conceitos são 
geralmente identificados na literatura como lamarckistas. Tal identificação já foi criticada por alguns autores tais como Bizzo (1991: 259) e Martins (1998: 19).

Bizzo (1991) especificamente não cai na tentação de identificar como lamarckistas a maior parte das respostas dos alunos. Entretanto, grande parte dos autores nesta área trabalha com a certeza desta identificação.

Veja-se, por exemplo, o trabalho de Jensen \& Finlay (1995: 153-156), que numa perspectiva de mudança conceitual dos alunos no tema da evolução, usam como estratégia argumentos históricos das teorias evolutivas, quando cometem o equívoco de usar um remanejamento posterior do programa darwiniano, com fatos e inferências, para contextualizar a teoria. Pior, na análise das respostas dos alunos identificam as lamarckistas e darwinistas, nesta última classificação, o conceito de mutação é associado à teoria darwiniana (op. cit.: 156, tab. 4). Ora, certamente, Darwin nunca trabalhou com este conceito. A teoria mutacionista foi desenvolvida numa fase de transição entre o darwinismo e o neodarwinismo, principalmente por Hugo de Vries, como uma teoria evolutiva antidarwinista, para depois ser remanejada teoricamente e incorporada ao programa neodarwinista.

$\mathrm{Na}$ perspectiva do presente trabalho, esta identificação é historicamente incorreta e equivocada. Como foi discutido anteriormente, o programa de pesquisa darwiniano, em seu campo de validade, também inclui as teorias do uso e desuso e da herança dos caracteres, no sentido de explicar os mecanismos do processo evolutivo, isto é, Darwin não considerava a teoria da seleção natural como mecanismo suficiente para explicar o processo (Gould, 2002: 67).

Esta confusão entre o programa de Darwin propriamente dito e o programa neodarwinista construído por seus seguidores é muito comum nos livros didáticos de Biologia e nas concepçôes de alunos e professores.

\section{Uma Possível Abordagem Teórica Analítica da Aprendizagem de Conceitos Relacionados à Evolução}

Por que razão os alunos quando confrontados com situaçães problemáticas envolvendo os mecanismos evolutivos apresentam respostas relacionadas com o uso e desuso e herança dos caracteres adquiridos?

Alguns autores já tentaram responder a esta questão: Gené (1991: 22), por exemplo, afirma que o fato deve-se à metodologia utilizada para aproximar-se da realidade, que não vai além da evidência e da simples observação e conclusōes tiradas a partir das mesmas. Esta pergunta, entretanto, não é tão simples de ser respondida.

Uma tentativa consistente para responder a estas e outras indagaçóes pode estar na Teoria dos Campos Conceituais de Vergnaud, como um instrumento de interpretação e compreensão de como os alunos conceitualizam.

Resumidamente apresentada, a teoria dos campos conceituais analisa os conceitos, as situações, os esquemas, os invariantes operatórios e as representaçôes existentes no processo de conceitualização dos sujeitos. $\mathrm{Na}$ análise dos conceitos é levada em conta a existência de três conjuntos de fatores: $\mathrm{S}$, é o conjunto de situaçôes que dão sentido ao conceito; I, é o conjunto de invariantes operatórios associados ao conceito e R é o conjunto de representaçôes simbólicas que representam os invariantes. Para estudar-se o desenvolvimento e o uso de um conceito ao longo da aprendizagem é necessário considerar estes três conjuntos de fatores simultaneamente.

As situaçôes dão sentido aos conceitos; inserindo-os em contexto sociocultural significativo, o conhecimento dos alunos é moldado pelas situaçôes e é nelas exercitado. Os esquemas 
constituem-se numa organização invariante do comportamento para uma determinada classe de situações. Os invariantes operatórios constituem-se de conceitos em ação e teoremas em ação, como proposições tidas como verdadeiras sobre o real; estes não são científicos, mas podem tornar-se conceitos científicos desde que explicitados e, finalmente, as representações, que podem ser corretas ou erradas, implícitas ou explícitas e se constituem em substitutas da realidade sendo feitas de teoremas em ação.

Assim, a construção do conhecimento consiste na progressiva construção de representações mentais homomórficas à realidade e progressivamente abstraíveis em termos de construtos conceituais expressáveis simbolicamente. Em tal processo de construção Vergnaud ressalta que os conceitos não se constituem isoladamente, mas se articulam em sistemas reticulados nos quais os elementos se interconectam, os campos conceituais (Vergnaud, 1990). Nesse sentido, nenhuma situação seria abordável cognitivamente com o recurso a um único conceito e nenhum conceito poderia ser restrito a uma única situação. Convém, de imediato, chamar a atenção para uma dupla acepção do termo teórico "campo conceitual" em Vergnaud: tal termo recobre tanto o campo de conceitos de que dispõe determinado indivíduo para a construção de significado referente a determinado aspecto por ele conhecido (acepção psicológica), quanto o campo de conceitos canônicos propostos pelo saber de referência em determinado campo epistêmico (acepção epistemológica). É no contexto desta última acepção que Vergnaud fará alusão, por exemplo, ao "campo conceitual das estruturas aditivas".

Tendo em vista as consideraçôes acima, podemos considerar, por exemplo, que as teorias do uso e desuso e a herança dos caracteres adquiridos como invariantes operatórios, ou mais precisamente, como teoremas em ação, como caracterizadores do campo conceitual que geralmente os alunos mobilizam diante de situaçóes envolvendo os mecanismos do processo evolutivo.

Como escreve Moreira (2002), a teoria dos campos conceituais enfatiza que a aquisição de conhecimento é moldada pelas situações e problemas previamente dominados e que esse conhecimento tem, portanto, muitas características contextuais. Assim, muitas de nossas concepçôes vêm das primeiras situações que fomos capazes de dominar ou de nossa experiência tentando modificá-las. No entanto, existe, provavelmente, uma lacuna considerável entre os invariantes que os sujeitos constroem ao interagir com o meio e os invariantes que constituem o conhecimento científico entre o campo conceitual disponível no início do processo de aprendizagem e o campo conceitual canônico a ser idealmente construído por estes aprendizes.

As concepções prévias dos alunos têm sido consideradas como erros, misconceptions, concepções ingênuas, concepções alternativas, em relação às concepções científicas. Para Vergnaud (2002) esta maneira de conceber o conhecimento prévio supõe a criança, o aluno ou o adulto aprendiz, como incompletos, imperfeitos ou deficientes em comparação a adultos especialistas. Essa abordagem, segundo ele, é ingênua e pouco produtiva em termos da abordagem psicológica do desenvolvimento conceitual. Seria muito mais frutífero considerar o sujeito como um sistema dinâmico, com mecanismos regulatórios capazes de assegurar seu progresso cognitivo. O que tudo isso quer dizer é que é normal que os alunos apresentem tais concepções e que elas devem ser consideradas como precursoras de conceitos científicos a serem adquiridos. A ativação desses precursores tem no professor um agente mediador importante, pois é ele quem coordenará o processo de transposição didática secundária (Chevallard, 1985), ou seja, o interfaceamento entre o saber canônico do qual o professor é representante institucionalmente reconhecido (exemplo, campo conceitual da Evolução do ponto de vista dominante em Biologia), e o campo conceitual disponível pelo grupo de alunos. Quatro aspectos de natureza epistemológica e psicopedagógica decorrem de imediato das presentes consideraçōes: 1. o que "sabe" o saber de referência; 2. o quanto o professor é referência (confiável...) 
deste saber; 3. o que sabem os alunos acerca do campo conceitual em questão; e finalmente 4 . como fazer, em termos de iniciativa didática, para que saber de referência e campo conceitual construído disponível por parte dos alunos dialoguem construtivamente.

Classificar apressadamente as concepções prévias dos alunos como meras misconceptions pode refletir um olhar que prioriza, nestas concepçōes destes alunos, o que elas ainda não são ou ainda não têm, em detrimento do que elas já são: tais concepções contêm teoremas e conceitos-em-ação que se ainda estão distantes do campo conceitual canônico, podem evoluir para eles. Porém, convém desde logo evitar o otimismo fácil: o hiato entre os esquemas cognitvos conceituais e pré-conceituais dos alunos e os conceitos compartilhados pela comunidade científica que "gerencia" o conhecimento científico savant, hegemônico ou "normal" (Khun, 1982: 29) é grande, de modo que o processo de desenvolvimento conceitual é necessariamente árduo e demorado. Não obstante, desejável e possível.

A teoria de Vergnaud parece ser, então, um bom referencial para análise das dificuldades dos alunos no que diz respeito à conceitualização do processo e dos mecanismos evolutivos. Tais dificuldades poderiam, por exemplo, ser examinadas em termos de esquemas (com seus invariantes operatórios, suportes representacionais e contextos de utilização) quer dizer, em termos de quais os conceitos e teoremas-em-ação os estudantes estariam usando na resolução de problemas e de quão distantes estariam dos conceitos e teoremas cientificamente aceitáveis. A avaliação de tal distância constituir-se-ia, por esse raciocínio, em etapa importante para o estabelecimento de um caminho ou estratégia de encaminhamento didático que auxiliasse os alunos nesse caminhar.

\section{Referências}

AMABIS, J. M.; MARTHO, G. R. Breve história das idéias evolucionistas. In: Biologia das populaçôes: genética, evolução e ecologia. São Paulo: Moderna, 1997. p. 218-238.

ASTOLFI, J. P.; DEVELAY, M. A didática das ciências. 4. ed. Campinas: Papirus, 1995. 132 p.

BIZZO, N. M. V. Ensino de evolução e história do darwinismo. 1991. 312 f. Tese (Doutorado em Educação) - Universidade de São Paulo, São Paulo, 1991.

BALDWIN, J. M. A new factor in evolution. American Naturalist, n. 30, p. 441-451; 536-553, 1896. Disponível em: http://psychclassics.Yorku.ca/Baldwin/history. Acesso em: 12 dez. 2004.

BIOLOGICAL SCIENCES CURRICULUM STUDY. Mecanismo da evolução: dois pontos de vista em conflito. In: Biologia: parte I. São Paulo: Edart, 1965. cap. 3, p. 38-53.

BLANC, M. Os herdeiros de Darwin. Lisboa: Teorema, 1991. 239 p.

BOWLER, P. J. The changing meaning of evolution. Journal History of Ideas, n. 36, p. 95-114, 1975.

. Darwin on man in the origin of species: a reply to Carl Bajema. Journal of the History of Biology, Dordrecht, v. 22, n. 3, p. 497-500, 1989.

BRITO, E. A.; FAVERETTO, J. A. Evolução biológica. In: Biologia: uma abordagem evolutiva e ecológica. São Paulo: Moderna, [19-1997]. cap. 8, p.164-195. 
BUCKHARDT JR., R. W. Lamarck, evolution, and polictics of science. Journal of the History of Biology, Dordrecht, n. 3, p. 275-298, 1970.

. The inspiration of Lamarck's belief in evolution. Journal of the History of Biology,

Dordrecht, n. 5, p. 413-418, 1972.

CANGUILHEM, G. Ideologia e racionalidade nas ciências da vida. Lisboa: Ediçōes 70, 1977. 126 p.

CHEVALARD, Y. La tranposition didactique. Grenoble: La Pensée Sauvage, 1985. 155 p.

CONRY, Y. Lamarck, penseur de frontière. Nuncius, Firenze, anno 9, n. 2, p. 559-592, 1994.

DA ROCHA FALCÃO, J. T. Elementos para uma abordagem psicológica do desenvolvimento de conceitos científicos e matemáticos. In: DIAS, M. G.; SPINILLO, A. G. (Org.). Tópicos em psicologia cognitiva. Recife: Editora Universitária da UFPE, 1996. p.141-167.

DARWIN, C. Variation of animals and plants under domestication. London: Murray, 1868. 2 v.

. The origin os species by means of natural selection. In: HUTCHINS, R. M. (Ed.). Great books of the western world. Chicago: Encyclopaedia Britannica, 1952. p. 1-254.

. The descent of man. In: HUTCHINS, R. M. (Ed.). Great books of the western world. Chicago: Encyclopaedia Britannica, 1952. p. 253-659.

. Origem das espécies. Porto: Lello \& Irmão, 1961. 506 p.

. A origem do homem e a seleção sexual. São Paulo: Hemus, 1974. 716 p.

FRACALANZA, H. Ciência e livros didáticos. Educação e Sociedade, São Paulo, n. 22, p. 138-147, 1985.

FUTUYMA, D. J. Biologia evolutiva. 2. ed. Ribeirão Preto: Sociedade Brasileira de Genética, 1995. 631 p.

GENÉ, A. Cambio conceptual y metodológico en la enseñanza y aprendizaje de la evolución de los seres vivos: un ejemplo concreto. Enseñanza de las Ciencias, Barcelona, v. 9, n. 1, p. 22-27, 1991.

GOULD, S. J. Darwin e os grandes enigmas da vida. São Paulo: Martins Fontes, 1987. 274 p.

. The structure of evolutuinary theory. Cambridge: The Belknap Press of Harvard University Press, 2002. 1393 p.

JENSEN, M. S.; FINLAY, F. N. Teaching evolution using historical arguments in a conceptual change strategy. Science Education, New York, v. 79, n. 2, p. 147-166, 1995.

KRASILCHIK, M. A evolução no ensino das ciências no período 1950-1985. In: O professor e o currículo das ciências. São Paulo: EPU, 1987. cap. 1, p. 5-25.

KHUN, T. A estrutura das revoluções científicas. São Paulo: Perspectiva, 1998. 237p. 
LAKATOS, I. La metodologia de los programas de pesquisa. Madrid: Alianza, 1987. 332 p.

MARTINS, L. A. C. P. Lamarck e as quatro leis da variação das espécies. Episteme, Porto Alegre, v. 2, n. 3, p. 33-54, 1997.

. A história da ciência e o ensino da biologia. Ciência \& Ensino, Campinas, n. 5, dez. 1998.

LEWONTIN, R. A tripla hélice: gene, organismo e ambiente. São Paulo: Companhia da Letras, 2002. 138 p.

MAYR, E. O desenvolvimento do pensamento biológico: diversidade, evolução e herança. Brasília:

Editora da Universidade de Brasília, 1998. 1107 p.

MOREIRA, M. A. A teoria dos campos conceituais de Vergnaud, o ensino de ciências e a pesquisa nesta área. Investigaçõos em Ensino de Ciências, Porto Alegre, v. 7, n. 1, 2002.

Disponível em: www.if.ufrgs.br/public/ensino/vol.17/n1/v7_n1_al.html. 2002.

SILVEIRA, F. L. A metodologia dos programas de pesquisa: a epistemologia de Imre Lakatos.

Caderno Catarinense de Ensino de Física, Florianópolis, v. 13, n. 3, p. 219-246, dez. 1996.

SOARES, J. L. Fixismo e evolucionismo. In: . Biologia no terceiro milênio: seres vivos, evolução e ecologia. São Paulo: Scipione, 1999. cap. 18, p. 259-284.

THUILLIER, J. A teoria da seleção natural. São Paulo: Edusp, 1994. 342 p.

UZUNIAN, A.; BIRNER, E. Evolução biológica: como os seres vivos evoluem. In: Biologia.

São Paulo: Harbra, 2001. cap. 55, p. 710-716.

VERGNAUD, G. La théorie des champs conceptuels. Recherches em Didactique des

Mathématiques, Grenoble, v. 10, n. 23, p. 133-170, 1990.

. La conceptualisation, clef de voûte des rapports entre pratique et théorie. In: ANALYSE des pratiques et professionnalité des enseignts. Paris: Les Actes de la DESCO, 2002. 